\title{
On residents' satisfaction with community health services after health care system reform in Shanghai, China, 2011
}

\author{
Zhijian $\mathrm{Li}^{1}$, Jiale $\mathrm{Hou}^{2}$, Lin $\mathrm{Lu}^{2}$, Shenglan Tang ${ }^{3}$, Jin $\mathrm{Ma}^{2 *}$ \\ From Universal Coverage: Can We Guarantee Health For All? \\ Bandar Sunway, Malaysia. 3-4 October 2011
}

\begin{abstract}
Background: Health care system reform is a major issue in many countries and therefore how to evaluate the effects of changes is incredibly important. This study measured residents' satisfaction with community health care service in Shanghai, China, and aimed to evaluate the effect of recent health care system reform.

Methods: Face-to-face interviews were performed with a stratified random sample of 2212 residents of the Shanghai residents using structured questionnaires. In addition, 972 valid responses were retrieved from internet contact. Controlling for sex, age, income and education, the study used logistic regression modeling to analyze factors associated with satisfaction and to explain the factors that affect the residents' satisfaction.

Results: Comparing current attitudes with those held at the initial implementation of the reform in this investigation, four dimensions of health care were analyzed: 1) the health insurance system; 2) essential drugs; 3) basic clinical services; and 4) public health services. Satisfaction across all dimensions improved since the reform was initiated, but differences of satisfaction level were found among most dimensions and groups. Residents currently expressed greater satisfaction with clinical service (average score $=3.79$, with 5 being most satisfied) and the public health/preventive services (average score=3.62); but less satisfied with the provision of essential drugs (average score $=3.20$ ) and health insurance schemes (average score $=3.23$ ). The disadvantaged groups (the elderly, the retired, those with only an elementary education, those with lower incomes) had overall poorer satisfaction levels on these four aspects of health care $(P<0.01) .25 .39 \%$ of the respondents thought that their financial burden had increased and $38.49 \%$ thought that drugs had become more expensive.

Conclusion: The respondents showed more satisfaction with the clinical services (average score $=3.79$ ) and public health services/interventions (average score=3.79); and less satisfaction with the health insurance system (average score=3.23) and the essential drug system (average score=3.20). Disadvantaged groups showed lower satisfaction levels overall relative to non-disadvantaged groups.
\end{abstract}

\section{Background}

\section{Policy background}

After the economic reform, which was launched in late 1970s, China's health care system has experienced several significant changes that have had profound implications on access to health care for the population [1].

\footnotetext{
* Correspondence: majin@shsmu.edu.cn

${ }^{2}$ School of Public Health, Shanghai Jiao Tong University, 200025, Shanghai, China

Full list of author information is available at the end of the article
}

From the early 1980 s to the early 2000 s, the financing of health care has gradually been driven by the introduction of a market economy, which had replaced a planned economy. Such a change in the financing of health care system has been seen as unsuccessful because since the 1980s and 90s equity in access to health care has worsened and cost escalation has become uncontrollable [1].

Over the past decade, the government of China has recognized these and other challenges in reforming its

\section{Biomed Central}


health care system. In 2009, it initiated a new round of health care system reforms which aimed to ensure that the State plays a critical role in guaranteeing universal coverage of essential health care and providing secure, efficient, convenient and affordable basic health care services [2]. Four aspects of health care system covering both urban and rural residents have been or continue to be either strengthened or established, as follows: 1) health insurance schemes; 2 ) national essential drug systems; 3) clinical service system; and 4) the public health/preventive service system. There has been significant progress made in these areas over the past three years and the context of each system will subsequently be explained.

First, regarding health insurance schemes, the basic health insurance system has almost attained universal coverage. After the reform, China developed three mainstream schemes: the Urban Employee Basic Medical Insurance (UEBMI), the Urban Resident Basic Medical Insurance (URBMI) and the New Rural Cooperative Medical Scheme (NRCMS). Additionally, Medical Financial Assistance (MFA) was created to assist the poor.

UEBMI, is jointly funded by employers and employees and uses social health insurance mechanisms. It forms risk-pooling units, which are created independently for each city or county/district. URBMI is financed by central and local governments in addition to individual premiums. It began as a pilot program in 2007 and the funding amount per capita is approximately RMB 150 to RMB 500 ( $\$ 1$ US=6.5 RMB) [3]. Like URBMI, NRCMS is jointly funded by central and local governments and premiums; however, it covers rural residents and was started in 2003. A majority of URBMI and NRCMS benefit packages cover only inpatient care, while an increasing number of Chinese cities and counties have expanded their benefit packages to include outpatient care. MFA is a government program providing supplemental support to the poor by paying health premiums and covering extra costs in seeking care for catastrophic illnesses.

Second, the national essential drug policy has been implemented nationwide. The national essential drugs list for primary health organizations comprises 307 medicines including chemical medicines, biological products and proprietary Chinese medicines [4]. The list specifies that primary care facilities in China are not allowed to earn any mark-up on the sale of essential drugs. The policy has been successful in most places of China, as the prices of essential drugs were reduced by approximately 16\%-30\% since it was implemented [4].

Third, public hospitals, particularly at local level, (i.e. country/district and township/sub-district level) were reformed to improve the efficiency and effectiveness of service provision. In 2009, the Chinese government promised to strengthen more than 300 county-level hospitals (including traditional Chinese medicine hospitals), over 1,000 central township hospitals and more than 12,000 village clinics. The goal is to have at least one general hospital from each county reaching an expected quality of care, and to have one to three standardized key health centers in each township [3].

Fourth, the reform has called for greater equality in the provision of public health interventions/services between urban and rural areas and between rich and poor areas within the next five years. Starting from 2009, actions have been taken to increase regular health checkups for senior citizens over 65; regular growth checkups on infants and children under three years of age; regular prenatal examinations and postnatal visits for pregnant and lying-in women; and guidance for prevention and disease control to patients with diseases such as hypertension, diabetes, mental disorders, HIV/ AIDS, and tuberculosis.

Overall, from a supply-side point of view, the reform is generally seen as successful. However, it is also important to determine the extent of the reform's success as experienced by the demand side. This paper attempts to answer this question by measuring the residents' satisfaction with community health services. Community health care services are key to the success of the reform because they are closely related to its four dimensions (health insurance system, essential drugs, basic clinical services and public health services). Community health service facilities not only help to maintain community residents' health by preventing disease, but also provide treatment for frequently-occurring illnesses and chronic diseases, in addition to rehabilitation and other public health services.

\section{Literature review}

There is a substantial amount of literature covering both patient satisfaction [5-12] and patient characteristics; in addition to aspects of care provided by hospitals related to patient satisfaction [13-21]. Bleich and her colleagues [13] used data from 21 European Union countries to investigate the determinants of satisfaction with the health care system as it relates to patient experience. The authors found that satisfaction with the health care system depends more on external factors such as patient expectations, health status and type of care required rather than on the experience of care as a patient. A study undertaken by Kroneman and others [14] assessed the extent to which direct access to health care services influences the satisfaction with general practitioner services in 18 European countries. The results showed that direct accessibility appeared to be important for patient satisfaction.

Several studies have also investigated patient satisfaction with services provided for specific diseases [22-28]. 
For example, regarding psychiatric services, Henderson and his team [22] compared patient satisfaction with community-based and hospital providers of care. They found that patients were more satisfied with the community-based service. Bentur et al. [23] examined the satisfaction with and access to community care of the chronically ill in Israel. The authors found that chronically ill and healthy respondents experienced the same satisfaction with community care services. Several studies [29-31] discussed the questionnaire's design, validity and reliability as it related to patient satisfaction which found that nursing and doctor categories were most notable, and several studies approached different aspects of patient satisfaction $[32,33]$.

There are very few studies that evaluate the health care system reform with regard to resident satisfaction, but several studies [34-36] have investigated reform impact in a few specific areas. Polluste et al. [34] evaluated primary health care reform in Estonia from patients' perspectives using interview data. Boika et al. [35] discussed the impact of health reforms on child health services in Europe. Hunter et al. [36] evaluated primary care reform in Ontario from the family physician viewpoint. There is no comprehensive evaluation that includes each dimension of the Chinese health care system reform from a service users' perspective.

On the other hand, with the deepening understanding of modern scientific management methods, hospital supervisors are paying increasing attention to patient suggestions and the doctor-patient consultation experience. This is because they are both important in a keenly competitive health care service market. Internationally, many scholars $[6,9,14-19,33]$ agree that patient satisfaction investigation and consultation experience investigation can be helpful in making sustainable improvements to medical services.

Currently a number of scholars have been exploring disease-based satisfaction indices by which medical service quality can be evaluated through a set of patient satisfaction indicator systems. Items to be evaluated include consultation environment, waiting time, medical staff attitude, medical technique, and therapeutic effect and medical cost among others. After repeated examination for health service delivery programs, both the Patient Satisfaction Questionnaire (Ware, PSQ) and the Quality of Care Monitors (Carey) were chosen as the basis for developing similar questionnaire [37]. Also, anchoring vignettes (short descriptions of hypothetical situations) are being used to adjust patient expectation for the purpose of achieving effective comparison among populations [38-40]. Finally, most investigations were done by a third-party using different questionnaires for different types of patient in order to ensure validity and effectiveness of the result. Thus, bias caused by complex interests of different stake-holders could be eliminated.
Although focused more on the clinical outcome, the NHS in England uses four disease-specific patientreported outcome measures (PROMs). PROMs measure quality of care from the patient perspective and calculate the health gain from a certain intervention. PROMs are measures of a patient health status or health-related quality of life and are typically short, self-completed questionnaires providing measurements at a single point in time. The health status information collected from patients before and after an intervention provides an indication of the quality of care delivered. Since PROMs have been made mandatory, the health gain reported from these four interventions has increased (i.e. the quality of care has become better after report was made necessary). Fitzpatrick et al. have outlined seven criteria for PROMS, which are reliability, validity, responsiveness, precision, interpretability, acceptability, and feasibility [41]. However, weaknesses remain in existing satisfaction investigations. Patient satisfaction is always evaluated only through patients' self-reporting using a questionnaire; however, results are largely influenced by patients' understanding of the questions, social environment, cultural environment, unpredictable factors during the investigation and individual subjective factors [37]. Patient satisfaction is highly related to patient expectations as patient satisfaction may change, even though the health service is itself unchanged. Patients have different expectations or reference criteria with regard to their health care service [42-45].

\section{Methods}

\section{Study design}

In order to overcome the shortcomings of satisfaction questionnaire design, this study formulated questionnaire and its index system through questionnaire investigation, literature survey and Delphi expert consultation. It was analyzed from qualitative and quantitative view. Items in the questionnaire included basic information from respondents, inquiries into satisfaction with the health insurance system, satisfaction with the essential drug system, satisfaction with the community clinical service, satisfaction with the basic public health service, residents' perception of the changes in community health care service quality and overall satisfaction with the implementation of health care system reform. One of the goals of this study was to identify the dimensions or items with which residents may or may not be satisfied. Thus, the key parts of the questionnaire included:

- seven questions on demographic factors to provide explanatory variables (sex, age, place of residence, job, education, income, illness suffered in the last two weeks);

- five questions on health insurance system covering ratio and range of reimbursement, convenience assessment to the reimbursement system; 
- four questions on the essential drug system covering drug list and satisfaction;

- twelve questions on aspects of the evaluation by residents of the community clinical service covering the reasons for choosing a particular clinic, medical factors (quality of medical care, etc.) and non-medical factors (waiting time, reasonable costs, etc.);

- seven questions on the public health service including the personal health file, health education, free examination (children, the elderly and pregnant women), prevention knowledge and guidance with respect to chronic disease;

- five questions on health care service improvement covering medical environment, attitude, communication, therapeutic effect and medicine demand;

- one question on overall satisfaction with care and services;

- and one open-ended question requesting comments or suggestions that the residents wished to express about the community health service.

\section{Sampling}

Through a stratified sampling method, eighteen districts of Shanghai were divided into three groups according to their location and level of economic development. Subsequently, one district was randomly selected from each group. These included one center district (Luwan District), one inner suburban district (Changning District) and one outer suburban district (Qingpu District).

In each sampled district, three community health service centers were randomly sampled, and 250 respondents from each service center were selected to respond to questionnaires. The sample size is determined by:

$n \approx \frac{\left(Z_{\alpha / 2}\right)^{2} \sigma^{2}}{E^{2}}$. Here $\mathrm{n}$ is sample size, $\sigma^{2}$ is variance, $\mathrm{E}$ is sampling error, $Z_{\alpha / 2}$ is confidence level. In the case of $95 \%$ confidence level and the sampling error is less than $5 \%$, the sample size was generally at 246 , so the survey choose 250 as the sample size. Trained investigators randomly distributed 2250 surveys and received 2212 effective responses. After website and email responses were included, the survey accumulated an additional 972 completed questionnaires. The online survey was also limited in the same three districts, and its proportion was similar with the field research. In total, 3184 responses were collected through field and online survey. As for the survey, a 5-point scale was used to rate the residents' satisfaction towards different aspects of the health system. "1" represented very dissatisfied, " 2 " quite dissatisfied, " 3 " satisfied, "4" quite satisfied, and " 5 " very satisfied.

\section{Limitations of study}

The study has several limitations. First, the influence of responses expectations and individual subjective factors was not considered when we designed investigation questionnaire and the email respondents were more well off and educated. Second, the selection of the respondents focused on only one city, Shanghai. Thus the results may not be generalizable to the entire country due to differences between cities and urban and rural distinctions. Third, the reform process has started relatively recently and, as a result, more time may be needed for these policies to take full effect.

\section{Research instruments}

Data were analyzed using an SAS computer statistical package, Version 9.1 (SAS Institute Inc, Cary, NC). The respondents were grouped by sex, age, education, place of residence (the capital city, urban or rural populations) and annual income. The Spearman correlation test was used to estimate the association between variables. We conducted a multivariate analysis of logistic regression to determine the independent effects on the level of satisfaction.

\section{Results}

\section{Characteristics of study population}

The respondents were grouped by sex, age, job status, education, income and whether or not they suffered illness in the two weeks prior to being surveyed. $41.55 \%$ were men and $41.81 \%$ were above 60 years of age. $45.04 \%$ were employed, $42.28 \%$ were retired and the rest were students or unemployed. The education distribution showed that $40.91 \%$ of those interviewed had elementary or less education (nine years or less), 29.91\% had secondary education (twelve years) and $29.18 \%$ had a post-secondary education (more than fifteen years). To explain the socio-economic group differences, the sample was divided into four income groups according to their annual income: less than US\$ 1,500 (22.75\%), US\$ 1,500-6,000 (55.58\%), US\$ 6,000-20,000 (18.67\%) and more than US\$20,000 (3\%).

The age of the respondents was significantly correlated with job status ( $\rho=0.61, \mathrm{p}<0.001)$ and education level ( $\rho=0.45, p<0.001)$. Significant correlation was also found between education and income level $(\rho=0.43, \mathrm{p}<0.001)$; education and job status $(\rho=0.39$, $\mathrm{p}<0.001)$; and between job status and income level ( $\rho=0.32, p<0.001$ ). Of the respondents, 1279 or $41.69 \%$ suffered illness in the previous two weeks to being surveyed.

Our sample represents the population who see a doctor in community health service center.

\section{Satisfaction with different services and facilities}

Residents' satisfaction measurement was divided into five dimensions (clinical service, public health service, drug delivery system, health insurance system and 
overall satisfaction). Table 1 shows the items and corresponding score of each dimension.

As seen in Table 2, after calculated the average scores of the subareas for each of the four categories, we found that the residents were generally satisfied to a relatively high degree with the clinical service, the next highest level was with the public health service; and the results showed less satisfaction with the essential drug system and the health insurance system. The highest satisfaction was with staff attitude $(3.98 \pm 0.69)$, and the next highest was with communication between physician and patient $(3.90 \pm 0.70)$ and the medical environment (3.86 \pm 0.69 ). Residents were least satisfied with the drug prices $(3.21 \pm 0.94)$, accessibility to drugs $(3.27 \pm 0.68)$, convenience of reimbursement (i.e. paid by the insurance or the government) $(3.29 \pm 0.83)$ and ratio of reimbursement $(3.30 \pm 0.80)$. The overall satisfaction related to the health care system was just above the median score $3(3.23 \pm 0.86)$.

Table 1 Demographic characteristic of respondents in Shanghai, 2011

\begin{tabular}{|c|c|c|}
\hline Characteristic & $\mathrm{N}$ & $(\%)$ \\
\hline \multicolumn{3}{|l|}{ Sex $($ missing $=88)$} \\
\hline men & 1342 & 43.35 \\
\hline \multicolumn{3}{|l|}{ Age group (missing=34) } \\
\hline$\leq 18$ & 53 & 1.68 \\
\hline $19-29$ & 354 & 11.24 \\
\hline $30-39$ & 347 & 11.02 \\
\hline $40-49$ & 463 & 14.70 \\
\hline $50-59$ & 616 & 19.56 \\
\hline$\geq 60$ & 1317 & 41.81 \\
\hline \multicolumn{3}{|l|}{ Place of Birth (missing=89) } \\
\hline Shanghai & 2518 & 81.36 \\
\hline Suburban & 318 & 10.27 \\
\hline Other cities & 179 & 5.78 \\
\hline Rural & 80 & 2.58 \\
\hline \multicolumn{3}{|l|}{ Employment status(missing=22) } \\
\hline Employed & 1424 & 45.04 \\
\hline Unemployed & 271 & 8.57 \\
\hline Retired & 1337 & 42.28 \\
\hline \multicolumn{3}{|l|}{ Education (missing=34) } \\
\hline Elementary or less & 1289 & 40.91 \\
\hline Secondary & 942 & 29.91 \\
\hline Post-secondary or above & 919 & 29.18 \\
\hline \multicolumn{3}{|l|}{ Income(missing=34) } \\
\hline Bottom quarter & 714 & 22.75 \\
\hline Second quarter & 1744 & 55.58 \\
\hline Third quarter & 586 & 18.67 \\
\hline Top quarter & 94 & 3.00 \\
\hline \multicolumn{3}{|c|}{ Suffer ill in two weeks(missing $=116$ ) } \\
\hline Yes & 1279 & 41.69 \\
\hline No & 1789 & 58.31 \\
\hline
\end{tabular}

Table 2 Main areas covered by the satisfaction scale

\begin{tabular}{lllll}
\hline Dimension & Item & N & Mean & S.D \\
\hline Clinical services & & & & \\
& Waiting time & 2203 & 3.73 & 0.75 \\
& Medical environment & 2193 & 3.86 & 0.69 \\
& Facility and equipment & 2197 & 3.70 & 0.75 \\
& Staff attitude & 2199 & 3.98 & 0.69 \\
& Communication & 2197 & 3.90 & 0.70 \\
& Therapy effect & 2193 & 3.81 & 0.70 \\
& Medical cost & 2203 & 3.65 & 0.77
\end{tabular}

Public health

services

\begin{tabular}{|c|c|c|c|}
\hline Community health education & 2801 & 3.73 & 0.8 \\
\hline $\begin{array}{l}\text { Community prevention } \\
\text { knowledge }\end{array}$ & 2798 & 3.74 & 0.7 \\
\hline Free examination for the elder & 2501 & 3.70 & \\
\hline $\begin{array}{l}\text { Free examination for the } \\
\text { children }\end{array}$ & 2220 & 3.59 & \\
\hline $\begin{array}{l}\text { Free examination for the } \\
\text { pregnant }\end{array}$ & 2192 & 3.59 & \\
\hline gular guidance to chronic & & & \\
\hline
\end{tabular}

Essential drug

system

\begin{tabular}{lllll} 
& Accessibility to medicine & 1688 & 3.27 & 0.68 \\
& Medicine price & 2680 & 3.21 & 0.94 \\
Health insurance & & & & \\
& & 1668 & 3.30 & 0.80 \\
& Ratio of reimbursement & 1642 & 3.29 & 0.83 \\
& Convenience to reimburse & 2736 & 3.23 & 0.86 \\
\hline
\end{tabular}

Note: To measure the satisfaction of different dimensions, a five-point scale was used.

\section{Services satisfaction by different residents}

Satisfaction scores for different dimensions and groups are shown in Table 3. The individual item satisfaction scores were aggregated into total mean scores for each of the four dimensions. The mean score for each dimension was analyzed by sex, age, place of birth, work status, education and income. Judged by different dimension scores, the results show that residents were less satisfied with the essential drug system and the health insurance system relative to the systems related to clinical and public health services/interventions. Scores were 3.20, 3.23, 3.79 and 3.62 respectively. The unemployed, those earning low incomes, born in a suburban setting and having received an elementary education or less, were found to have relatively low satisfaction with all four dimensions of the health care system. Residents who were women, aged over 60 , retired, born in urban settings, and in the third-quarter income level (US\$ 6,000-20,000), were more satisfied with the medical services. Residents who were women, aged over 60 , retired, born in urban settings, received a secondary education and at the second quarter income level (US\$ 1,500-6,000) were more satisfied with the public health services/interventions. 
Table 3 Comparison of satisfaction between dimensions and groups

\begin{tabular}{|c|c|c|c|c|c|}
\hline & \multicolumn{5}{|c|}{ Mean Score of the Community Residents' Satisfaction with the Health Care System } \\
\hline & Clinical Service & Public Health Service & Essential drug System & Health insurance & Overall Satisfaction \\
\hline \multicolumn{6}{|l|}{ Sex } \\
\hline Men & 3.79 & 3.65 & 3.23 & 3.30 & 3.25 \\
\hline Women & 3.85 & 3.71 & 3.20 & 3.30 & 3.22 \\
\hline \multicolumn{6}{|l|}{ Age } \\
\hline$\leq 60$ & 3.81 & 3.63 & 3.23 & 3.33 & 3.25 \\
\hline$\geq 60$ & 3.83 & 3.73 & 3.19 & 3.21 & 3.20 \\
\hline \multicolumn{6}{|l|}{ Place of birth } \\
\hline Urban & 3.84 & 3.72 & 3.23 & 3.23 & 3.24 \\
\hline Suburban & 3.66 & 3.51 & 3.08 & 3.15 & 3.18 \\
\hline Migrant worker & 3.70 & 3.53 & 3.31 & 3.35 & 3.23 \\
\hline Rural & 3.74 & 3.52 & 3.25 & 3.27 & 3.27 \\
\hline \multicolumn{6}{|l|}{ Employment } \\
\hline Employed & 3.74 & 3.56 & 3.25 & 3.38 & 3.23 \\
\hline Unemployed & 3.65 & 3.37 & 3.15 & 2.61 & 2.89 \\
\hline Retired & 3.89 & 3.84 & 3.20 & 3.35 & 3.27 \\
\hline \multicolumn{6}{|l|}{ Education } \\
\hline Elementary or less & 3.82 & 3.39 & 3.24 & 3.19 & 3.23 \\
\hline Secondary & 3.82 & 3.73 & 3.23 & 3.34 & 3.26 \\
\hline Post-secondary or above & 3.82 & 3.63 & 3.15 & 3.29 & 3.16 \\
\hline \multicolumn{6}{|l|}{ Income } \\
\hline Bottom quarter & 3.68 & 3.48 & 3.20 & 3.10 & 3.13 \\
\hline Second quarter & 3.86 & 3.75 & 3.19 & 3.34 & 3.24 \\
\hline Third quarter & 3.91 & 3.74 & 3.33 & 3.43 & 3.34 \\
\hline Top quarter & 3.76 & 3.72 & 3.02 & 3.20 & 2.99 \\
\hline Average score & 3.79 & 3.62 & 3.20 & 3.23 & 3.20 \\
\hline
\end{tabular}

Note: To measure the satisfaction of subgroups, a five-point scale was used.

Residents, who were men, aged under 60 , born in rural settings, possessing an elementary or less education and at the third quarter income level were more satisfied with the essential drug system. Residents, who were under 60 years of age, workers not originally from Shanghai, employed, possessing a secondary education and at the third quarter income level were more satisfied with the health insurance system. The difference in the overall satisfaction score between groups was smaller, as shown in the last column of Table 3. On all scales, the community health care system earned mean scores of 3.20. The score was marginally above the midpoint (a score below 3 would indicate a negative evaluation).

\section{Factors associated with the residents' perceptions of service improvement}

The study further investigated the residents' perceptions to the health service improvement. Out of all the respondents, $47.64 \%$ believed their access to drugs to have either not changed or decreased. Only one-third believed that it had changed for the better, and $19.81 \%$ considered it difficult to estimate. In terms of health insurance coverage, more than $53 \%$ of respondents thought that little had changed; more than $8 \%$ of respondents believed that the reimbursement rate had lowered; only $15.37 \%$ of respondents thought that the rate had increased, and $22.86 \%$ thought it was difficult to determine.

Residents' perception with out-of-pocket expenditures and medicine prices was even lower. The percentage of respondents who thought they changed for the worse in these two aspects were $25.39 \%$ and $38.49 \%$, respectively; $37.66 \%$ and $27.89 \%$ of respondents thought that there were no significant changes; only $17.14 \%$ and $14.82 \%$ felt that they changed for the better; and $19.81 \%$ and $18.80 \%$ thought the determination was difficult to make. Thus, compared with the price of medicines and the ratio of reimbursement, people have a relative high assessment on the medical environment, medical level and staff attitude; more than half the interviewers reported positive response. This result is thought to have arisen because the patients pay for the services mostly on a fee-for-service basis, so there was no incentive for the health service provider to control the costs. Although the government took some measures to control medicine and service prices, the result was still unsatisfactory according to the survey results. $60.61 \%$ of the retired and $49.49 \%$ of the unemployed 
reported negative response to the essential drug system. Indeed, even for the employed respondents, the degree of perception improvement with the essential drug delivery system was obviously lower than with other items. The details are shown in Table 4.

\section{Relationship between satisfaction and resident characteristics}

The mean score for each dimension was analyzed by sex, age, place of residence, work status, education and income. From the results of the logistic regression models, being male, over age 50 , from a rural setting, being retired, having an elementary education and having a low level of income were found to have an independent negative effect on every dimension of the health service system $(P<0.01)$. There were significant positive effects $(\mathrm{P}<0.01)$ for local farmers, migrant workers, those with higher education level and high income. In particular, the migrant worker group reported greater satisfaction because they generally have graduated from university and can find stable jobs in cities. The results show that vulnerable groups have less accessibility to community health services, highlighting the need for more attention to be paid to this area during the reform process. The analysis results are shown in Table 5 .

\section{Results of the open ended question}

In order to understand the satisfaction with community health services comprehensively, the questionnaire designed an open ended question. Compared with the beginning of the reform, the biggest difference is the improvement in terms of convenience, medical environment and staff attitude. Most of the questions focused on access to drugs, the reimbursement rate, out of pocket payment rate and medicine price.

\section{Discussion}

The health care system in China has made some progress since the government initiated the reforms. As noted in Table 3, respondents showed relative high satisfaction with the overall community health services (average score $=3.20$ ). However, this finding was not inconsistent across all of the four main dimensions of services. The respondents showed more satisfaction with the clinical services (average score $=3.79$ ) and public health services/interventions (average score $=3.79$ ); and less satisfaction with the essential drug system (average score $=3.20$ ) and health insurance system (average score $=3.23$ ). Only one-third of respondents found the drug delivery system to have improved, and one-third believed that there was no change. More than half the respondents thought that the health insurance system had undergone no change or worsened.

The residents report lower satisfaction with the essential drug system. Out of the 307 medicines on the list, only 205 of them are chemical and biological medicines (the rest are traditional Chinese medicines). The list is too narrow to meet the residents' demand for basic medicines. Particularly, demand is unmet for medicines used to treat children and chronic illnesses. It was found that the health insurance system should enhance the reimbursement ratio through lowering the deductible, raising the ceiling amount covered and/or expanding the reimbursement range of diseases, surgery and medical examination in order to enhance the level of protection [46].

The results also demonstrate that disadvantaged groups (the elderly, retired, those only with an elementary level of education and those earning a lower level of income) expressed poorer response in overall satisfaction across every dimension. This result of vulnerable groups reporting less satisfaction seems logical and consistent with the reality of China. As most hospitals mainly received payment based on a fee-for-service basis, they have little incentive to control costs, although an increasing number of hospitals are now paid for by other provider payment methods. Additionally, exacerbating the problem, the health insurance system simply makes payments and does not play intentional role in constraining medical costs (average score $=3.21$ ). Finally, the ratio of reimbursement (average score $=3.30$ ) did not increase greatly since the reform.

Table 4 Respondents' perceptions to the change of the health service improvement

\begin{tabular}{|c|c|c|c|c|}
\hline & \multicolumn{4}{|c|}{ Opinion(percentage) } \\
\hline & Change worse & No change & Change better & Hard to say \\
\hline Medical environment & 1.34 & 34.57 & 55.21 & 8.88 \\
\hline Technical level & 1.15 & 34.42 & 53.92 & 10.52 \\
\hline Staff attitude & 1.04 & 28.22 & 62.45 & 8.29 \\
\hline Therapy effect & 1.14 & 34.82 & 48.65 & 15.39 \\
\hline Medicine demand & 10.64 & 36.82 & 32.73 & 19.81 \\
\hline \%of reimbursement & 8.17 & 53.60 & 15.37 & 22.86 \\
\hline$\%$ of out of pocket payment & 25.39 & 37.66 & 17.14 & 19.81 \\
\hline Medicine price & 38.49 & 27.89 & 14.82 & 18.80 \\
\hline
\end{tabular}


Table 5 Satisfaction with the four dimensions of the health service system and with the overall evaluation, by background variables (logistic regression)

\begin{tabular}{|c|c|c|c|c|c|c|c|c|c|c|}
\hline & \multicolumn{2}{|c|}{ Clinical Service } & \multicolumn{2}{|c|}{ Public Health Service } & \multicolumn{2}{|c|}{ Medicine Delivery System } & \multicolumn{2}{|c|}{ Health Insurance } & \multicolumn{2}{|c|}{ Overall satisfaction } \\
\hline & B & $\begin{array}{l}\text { Odds ratio } \\
(95 \% \mathrm{Cl})\end{array}$ & B & $\begin{array}{l}\text { Odds ratio } \\
(95 \% \mathrm{Cl})\end{array}$ & $\mathrm{B}$ & $\begin{array}{l}\text { Odds ratio } \\
(95 \% \mathrm{Cl})\end{array}$ & $\mathrm{B}$ & $\begin{array}{l}\text { Odds ratio } \\
(95 \% \mathrm{Cl})\end{array}$ & $\mathrm{B}$ & $\begin{array}{c}\text { Odds ratio } \\
(95 \% \mathrm{Cl})\end{array}$ \\
\hline Male & -0.03 & $\begin{array}{c}0.82 \\
(0.70-0.96)\end{array}$ & -0.03 & $\begin{array}{c}0.94 \\
(0.81-1.10)\end{array}$ & -0.05 & $\begin{array}{c}0.91 \\
(0.78-1.06)\end{array}$ & -0.11 & $\begin{array}{c}0.81^{* *} \\
(0.69-0.94)\end{array}$ & -0.10 & $\begin{array}{c}0.82 \\
(0.70-0.96)\end{array}$ \\
\hline Age $\geq 50$ & -1.19 & $\begin{array}{c}0.96^{* *} \\
(0.70-1.30)\end{array}$ & -0.19 & $\begin{array}{c}0.88^{* *} \\
(0.65-1.21)\end{array}$ & -0.15 & $\begin{array}{c}0.87^{* *} \\
(0.64-1.18)\end{array}$ & -0.05 & $\begin{array}{c}1.03^{* *} \\
(0.75-1.40)\end{array}$ & -0.07 & $\begin{array}{c}0.95^{* *} \\
(0.70-1.30)\end{array}$ \\
\hline Alien peasants & -0.08 & $\begin{array}{c}0.97^{* *} \\
(0.55-1.72)\end{array}$ & -0.08 & $\begin{array}{c}0.94^{* *} \\
(0.53-1.66)\end{array}$ & -0.03 & $\begin{array}{c}1.01^{* *} \\
(0.57-1.79)\end{array}$ & -0.001 & $\begin{array}{c}0.91^{* *} \\
(0.52-1.60)\end{array}$ & -0.02 & $\begin{array}{c}0.97^{* *} \\
(0.55-1.72)\end{array}$ \\
\hline Local peasants & 0.32 & $\begin{array}{c}1.42^{* *} \\
(1.10-1.84)\end{array}$ & 0.33 & $\begin{array}{c}1.41^{* *} \\
(1.10-1.82)\end{array}$ & 0.30 & $\begin{array}{c}1.39^{* *} \\
(1.09-1.79)\end{array}$ & 0.15 & $\begin{array}{c}1.06^{* *} \\
(0.83-1.37)\end{array}$ & 0.02 & $\begin{array}{c}1.02^{* *} \\
(0.79-1.30)\end{array}$ \\
\hline Retired & -0.37 & $\begin{array}{c}0.93^{* *} \\
(0.58-1.48)\end{array}$ & 0.23 & $\begin{array}{c}0.66^{* *} \\
(0.41-1.07)\end{array}$ & 0.06 & $\begin{array}{c}1.22^{* *} \\
(0.77-1.95)\end{array}$ & -0.03 & $\begin{array}{c}0.64^{* *} \\
(0.40-1.02)\end{array}$ & -0.15 & $\begin{array}{c}0.93^{* *} \\
(0.58-1.48)\end{array}$ \\
\hline Alien worker & 0.28 & $\begin{array}{c}1.26^{* *} \\
(0.63-2.50)\end{array}$ & 0.10 & $\begin{array}{c}0.92^{* *} \\
(0.46-1.84)\end{array}$ & 0.16 & $\begin{array}{c}1.34^{* *} \\
(0.68-2.65)\end{array}$ & 0.09 & $\begin{array}{c}0.95^{* *} \\
(0.48-1.85)\end{array}$ & 0.16 & $\begin{array}{c}1.25^{* *} \\
(0.64-2.46)\end{array}$ \\
\hline Elementary education & -0.38 & $\begin{array}{c}0.69^{* *} \\
(0.53-0.92)\end{array}$ & -0.38 & $\begin{array}{c}0.74^{* *} \\
(0.56-0.97)\end{array}$ & -0.45 & $\begin{array}{c}0.77^{* *} \\
(0.59-1.01)\end{array}$ & -0.37 & $\begin{array}{c}0.59^{* *} \\
(0.42-0.83)\end{array}$ & -0.38 & $\begin{array}{c}0.59 * * \\
(0.42-0.82)\end{array}$ \\
\hline Post-secondary or above & 0.22 & $\begin{array}{c}1.16^{* *} \\
(0.86-1.57)\end{array}$ & 0.34 & $\begin{array}{c}1.27^{* *} \\
(0.95-1.71)\end{array}$ & 0.38 & $\begin{array}{c}1.29 * * \\
(0.96-1.72)\end{array}$ & 0.24 & $\begin{array}{c}1.08^{* *} \\
(0.81-1.45)\end{array}$ & 0.28 & $\begin{array}{c}1.14^{* *} \\
(0.85-1.53)\end{array}$ \\
\hline Bottom quarter income & -0.01 & $\begin{array}{c}1.38^{* *} \\
(1.10-1.72)\end{array}$ & -0.01 & $\begin{array}{c}1.43^{* *} \\
(1.14-1.78)\end{array}$ & -0.24 & $\begin{array}{c}1.37^{* *} \\
(1.10-1.71)\end{array}$ & -0.85 & $\begin{array}{c}1.42^{* *} \\
(1.14-1.77)\end{array}$ & -0.06 & $\begin{array}{c}1.38^{* *} \\
(1.10-1.72)\end{array}$ \\
\hline Top quarter income & 0.40 & $\begin{array}{c}2.41^{* *} \\
(1.48-3.94)\end{array}$ & 0.39 & $\begin{array}{c}2.13^{* *} \\
(1.31-3.46)\end{array}$ & 0.34 & $\begin{array}{c}1.98^{* *} \\
(1.23-3.18)\end{array}$ & 0.47 & $\begin{array}{c}2.48^{* *} \\
(1.54-3.99)\end{array}$ & 0.35 & $\begin{array}{c}2.08^{* *} \\
(1.28-3.38)\end{array}$ \\
\hline
\end{tabular}

* $P<0.05$, * $P<0.01$

The government chose a tender system in order to decrease the price of medicines [47] and to hopefully make the medicine procurement process more transparent and fair. However, there are still many problems with the implementation of the reforms leading to the policies not fully realizing the desired effect. For example, problems include a single supplier monopoly in one city, collusion between a hospital and pharmaceutical manufacturer and between a supplier and health bureau, and a lack of supervision by the local government [48].

Additionally, the residents generally showed a high degree of satisfaction with communication (average score $=3.90$ ) and staff attitudes (average score $=3.98$ ). It was found that appropriate levels of communication can reduce patients' anxiety and increase their satisfaction with health care services. This is consistent with previous studies [31]. Although, residents' satisfaction with the clinical services and public health services appears to be greater overall than satisfaction with the medicine supply system; there were still some items with regard to the medical care service and public health service which had satisfaction values lower than average (e.g. the equipment and facility, the medical cost, waiting time, free examination to for children and pregnant women).

For this reason, it is recommended that the government should concentrate on improving the service related to the above factors to produce greater satisfaction (e.g. vulnerable groups and the price of medicine). The government should also promote fairness and accessibility of medical service between different groups. Additionally, it needs to determine all possible avenues to increase the income of the poor(less than US $\$ 1,500$ and US\$1,500-6,000), reduce unemployment, decrease medicine prices and increase the ratio of reimbursement. This study also shows that, for the elderly, additional financial subsidization must be supplied by government. Quality of care was another important aspect of residents' perception of care in all the study items, and it was also an important factor affecting the residents' satisfaction. It is necessary to further improve medical staff education through technical training in order to increase the quality of therapy and thus to meet residents' demands.

\section{Conclusion}

In general, from a demand-side point of view, the reform has made some progress and residents' satisfaction has improved since the government initiated the new round reform. But differences of satisfaction level were found among most dimensions and groups. Residents are less satisfied with the provision of drugs at urban community health service centers and health insurance schemes, compared to clinical service delivery systems and public health/preventive services. Disadvantaged groups asserted lower satisfaction levels overall relative to non-disadvantaged groups.

This study provides a practical measure of satisfaction with specific dimensions of health care system. We hope 
that it will provide health decision-makers with empirical evidence to develop informed policies to tackle these challenges. Further efforts are needed to develop an ever-changing constructive evaluation of patient satisfaction with community health care and with Chinese health care system reform. Thus, these results require further follow-up.

\section{Acknowledgements}

This article has been published as part of BMC Public Health Volume 12 Supplement 1, 2012: Universal Coverage: Can We Guarantee Health For All?. The full contents of the supplement are available online at http://www. biomedcentral.com/bmcpublichealth/supplements/12/S1.

\section{Funding}

This work was supported by the Shanghai Municipal government, China. The sponsor had no role in the study design, data collection, analysis or manuscript writing.

\section{Author details}

'Antai College of Economics and Management, Shanghai Jiao Tong University, 200030, Shanghai, China. ${ }^{2}$ School of Public Health, Shanghai Jiao Tong University, 200025, Shanghai, China. ${ }^{3}$ Duke Global Health Institute, Duke University, NC 27708, Durham, USA.

\section{Authors' contributions}

ZL participated in the design, the acquisition, analysis and interpretation of data, and drafted the manuscript, JH collected the data of the residents and drafted part of the manuscript, JH and LL reviewed the manuscript, ST reviewed the manuscript and provided some comments, as well as participating in the finalization of the paper, JM participated in the design and reviewed the manuscript. All authors have read and approved the final manuscript.

\section{Competing interests}

The authors declare that they have no competing interests.

Published: 22 June 2012

\section{References}

1. Cao RG: The Thirty years of China's Health Reform. Chinese Hospital 2008, 9:1-8.

2. The Central People's Government, China. [http://www.gov.cn/jrzg/200904/06/content_1278721.htm], (2 August 2011, date last accessed).

3. The National People's Congress, China. [http://www.npc.gov.cn/npc/ xinwen/2010-12/25/content_1612569.htm], (2 August 2011, date las accessed)

4. The Central People's Government, China. [http://www.gov.cn/gzdt/200908/18/content_1395423.htm], (2 August 2011, date last accessed).

5. Etter Jean Francois, Perneger Thomas V: Quantitative and Qualitative Assessment Patient Satisfaction in a Managed Care Plan. Eval Program Plann 1997, 20:129-135.

6. Yildiz Zeki, Erdogmus Senol: Measuring Patient Satisfaction of the Quality of Health Care: A Study of Hospitals in Turkey. J Med Syst 2004, 28:581-589.

7. Langen Ingrid, Myhren Hilde, Ekeberg Øivind, et al: Patient's satisfaction and distress compared with expectations of the medical staff. Patient Educ Couns 2006, 63:118-125.

8. Zhao Mei, Haley D Rob, Nolin JoAnn M, et al: Utilization, cost, payment, and patient satisfaction of rehabilitative services in Shandong, China. Health Policy 2009, 93:21-26.

9. Mpinga Emmanuel Kabengele, Chastonay Philippe: Satisfaction of patients: A right to health indicator? Health Policy 2011, 100:144-150.

10. Andaleeb Syed Saad, Siddiqui Nazlee, Khandakar Shahjahan: Patient Satisfaction with Health Services in Bangladesh. Health Policy Plann 2007, 22:263-273.

11. Harms C, Young JR, Amsler F, et al: Improving anaesthetists' communication skills. Anaesthesia 2004, 59:166-72.
12. Pilpel D: Hospitalized patients' satisfaction with caregivers' conduct and physical surroundings. J Gen Intern Med 1996, 11:312-4.

13. Bleich Sara N, Ozaltinb Emre, Murray Christopher JL: How does satisfaction with the health-care system relate to patient experience? Bull World Health Organ 2009, 87:271-278.

14. Kroneman Madelon W, Maarse Hans, van der Zee Jouke: Direct access in primary care and patient satisfaction: A European study. Health Policy 2006, 76:72-79.

15. Rahmqvist Mikael, Bara Ana Claudia: Patient Characteristics and Quality Dimensions Related to Patient Satisfaction. Int J Qual Health Care 2010, 22:86-92.

16. Tung Yuchi, Chang Guannming: Patient Satisfaction with and Recommendation of a Primary Care Provider: Associations of Perceived Quality and Patient Education. Int I Qual Health Care 2009, 21:206-213.

17. Cheng Shou Hsia, Yang Ming Chin, Chiang Tung Liang: Patient Satisfaction with and Recommendation of a Hospital: Effects of Interpersonal and Technical Aspects of Hospital Care. Int I Qual Health Care 2003, 15:345-355.

18. Westaway Margaret S, Rheeder Paul, Van Zyl Danie G, et al: International and Organizational Dimensions of Patient Satisfaction: the Moderating Effects of Health Status. Int I Qual Health Care 2003, 15:337-344.

19. Sack C, Scherag A, Lutkes $P$, et al: Is There an Association Between Hospital Accreditation and Patient Satisfaction with Hospital Care? A Survey of 37000 Patients Treated by 73 Hospitals. Int I Qual Health Care 2011, 23:1-6.

20. Moret Leila, Nguyen Jean Michel, Volteau Christelle, et al: Evidence of a Non-linear Influence of Patient Age on Satisfaction with Hospital Care. Int I Qual Health Care 2007, 19:382-389.

21. Newman Robert D, Gloyd Stephen, Nyangezi Julio M, et al: Satisfaction with Outpatient Health Care Services in Manica Province, Mozambique. Health Policy Plann 1998, 13:174-180.

22. Henderson $C$, Phelan M, Loftus $L$, et al: Comparison of patient satisfaction with community-based vs. hospital psychiatric services. Actu Psychiat Scand 1999, 99:188-195.

23. Bentur Netta, Gross Revital, Brammli-Greenberg Shuli: Satisfaction with and access to community care of the chronically ill in Israel's health system. Health Policy 2004, 67:129-136.

24. Skarstein J, Dahl AA, Laading J, et al: Patient satisfaction in hospitalized cancer patients. Acta Oncol 2002, 41:639-45.

25. Asgari Maryam M, Bertenthal Daniel, Sen Saunak, et al: Patient Satisfaction After Treatment of Nonmelanoma Skin Cancer. Dermatol Surg 2009, 7:1041-1049

26. Sadjadian A, Kaviani A, Yunesian M, et al: Patient satisfaction: a descriptive study of a breast care clinic in Iran. Eur J Cancer Care 2004, 13:163-168.

27. Wessels H, DE Graeff A, Groenewegen G, et al: Impact of Integration of Clinical and Outpatient Units on Cancer Patient Satisfaction. Int I Qual Health Care 2010, 22:358-364.

28. Whitworth J, Pickering H, Mulwanyi F, et al: Determinants of Attendance and Patient Satisfaction at Eye Clinics in South-western Uganda. Health Policy Plann 1999, 14:77-81.

29. Erci Behice, Ciftcioglu Sibel: Psychometric Evaluation of the Primary Health-care Satisfaction Scale in Turkish Women. Int I Qual Health Care 2010, 22:500-506.

30. Antoniotti Stephanie, Barrau Karine Baumstarck, Simeoni Marie Claude, et al Validation of a French Hospitalized Patients' Satisfaction Questionnaire: the QSH-45. Int I Qual Health Care 2009, 21:243-252.

31. Dufrene Roxane L: An evaluation of a Patient Satisfaction Survey: Validity and Reliability. Eval Program Plann 2000, 23:293-300.

32. Atkinson Sarah, Haran Dave: Individual and District Scale Determinants of Users' Satisfaction with Primary Health Care in Developing Countries. Soc Sci Med 2005, 60:501-513.

33. Pink GH, Murray MA, McKillop I: Hospital Efficiency and Patient Satisfaction. Health Serv Manage Res 2003, 16:24-38.

34. Polluste Kaja, Kalda Ruth, Lember Margus: Evaluation of Primary Health Care Reform in Estonia from Patients' Perspective: Acceptability and Satisfaction. Croat Med J 2004, 45:582-587.

35. Rechel Boika, Spencer Nick, Blackburn Clare, et al: Impact of Health Reforms on Child Health Service in Europe: the Case of Bulgaria. Eur J Public Health 2009, 19:326-330.

36. Hunter Duncan JW, Shortt Samuel ED, Walker Peter M, et al: Family Physician Views about Primary Care Reform in Ontario: a Postal 
Questionnaire.[http://www.biomedcentral.com/1471-2296/5/2], (2 August 2011, date last accessed).

37. David W, Lesley H: Measure of need and outcome for primary health care. Oxford: Oxford University Press; 1992, 230-259.

38. Gary K, Jonathan W: Comparing Incomparable Survey Responses: Evaluating and Selecting Anchoring Vignettes. Political Analysis 2007 1:46-66.

39. The Anchoring Vignettes Website. [http://gking.harvard.edu/vign/], (25 August 2008, date last accessed).

40. The Anchoring Vignettes Website: What Has to Go Wrong for Anchoring Vignette Corrections to Bias My Results?. [http://beta.gking.harvard.edu/ vign/faq/What_has_to.html], (2 June 2012, date last accessed).

41. Elizabeth G, Ray F: A structured review of patient-reported outcome measures for people with asthma: an update 2009. University of Oxford; 2009.

42. Rubin HR, Ware JE, Nelson EC, et al: The patient judgments of hospital quality (PJHQ) questionnaire. Med Care 1990, 28:S17-8.

43. Arnetz JE, Arnetz BB: The development and application of a patient satisfaction measurement system for hospital wide quality improvement. Int J Qual Health Care 1996, 8:555-566.

44. Hendriks AA, Oort FJ, Vrielink MR, et al: Reliability and validity of the Satisfaction with Hospital Care Questionnaire. Int I Qual Health Care 2002, 14:471-482.

45. Gonzalez N, Quintana JM, Bilbao A, et al: Development and validation of an in-patient satisfaction questionnaire. Int I Qual Health Care 2005, 17:465-472.

46. Xinhua press. The deductible should further decrease. [http://news xinhuanet.com/comments/2009-07/10/content_11683844.htm], (accessed Nov.2011).

47. Tang S, Tao J, Bekedam H: Controlling Cost Escalation of Healthcare: Making Universal Health Coverage Sustainable in China. BMC Public Health

48. Wang Yong, Gong Xianwen: Game Model between hospital and patients. Journal of Chongqing University 2006, 6:34-38.

doi:10.1186/1471-2458-12-S1-S9

Cite this article as: Li et al:: On residents' satisfaction with community health services after health care system reform in Shanghai, China, 2011. BMC Public Health 2012 12(Suppl 1):S9.

\section{Submit your next manuscript to BioMed Central and take full advantage of:}

- Convenient online submission

- Thorough peer review

- No space constraints or color figure charges

- Immediate publication on acceptance

- Inclusion in PubMed, CAS, Scopus and Google Scholar

- Research which is freely available for redistribution

Submit your manuscript at www.biomedcentral.com/submit
Biomed Central 